Article

\title{
Superplasticity at Intermediate Temperatures of ZK60 Magnesium Alloy Processed by Indirect Extrusion
}

\author{
César Palacios-Trujillo ${ }^{1}$, José Victoria-Hernández ${ }^{2,3}$, David Hernández-Silva ${ }^{1, *}$, Dietmar Letzig ${ }^{2,3}$ \\ and Marco A. García-Bernal ${ }^{4, *}$ \\ 1 Department of Metallurgical Engineering, Instituto Politécnico Nacional, ESIQIE, UPALM EDIF. 7, \\ 07738 Mexico City, Mexico; cpalaciost0900@alumno.ipn.mx or cpt17_azul@hotmail.com \\ 2 Institute of Material and Process Design, Helmholtz-Zentrum Geesthacht, Max-Planck-Strasse 1, \\ D-21502 Geesthacht, Germany; jose.victoria-hernandez@hzg.de (J.V.-H.); dietmar.letzig@hzg.de (D.L.) \\ 3 Magnesium Innovation Centre MagIC, Helmholtz-Zentrum Geesthacht, Max-Planck-Strasse 1, \\ D-21502 Geesthacht, Germany \\ 4 SEPI, Instituto Politécnico Nacional, ESIME Unidad Ticomán, Av. Ticomán No. 600, Col. San José Ticomán, \\ 07340 Mexico City, Mexico \\ * Correspondence: dhernandez@ipn.mx or dhs07670@yahoo.com (D.H.-S.); magarciabe@ipn.mx or \\ magarciabe@gmail.com (M.A.G.-B.)
}

check for

updates

Citation: Palacios-Trujillo, C.;

Victoria-Hernández, J.;

Hernández-Silva, D.; Letzig, D.;

García-Bernal, M.A. Superplasticity at

Intermediate Temperatures of ZK60

Magnesium Alloy Processed by

Indirect Extrusion. Metals 2021, 11,

606. https://doi.org/10.3390/

met11040606

Academic Editor: Daolun Chen

Received: 1 February 2021

Accepted: 20 February 2021

Published: 9 April 2021

Publisher's Note: MDPI stays neutral with regard to jurisdictional claims in published maps and institutional affiliations.

Copyright: (c) 2021 by the authors. Licensee MDPI, Basel, Switzerland. This article is an open access article distributed under the terms and conditions of the Creative Commons Attribution (CC BY) license (https:// creativecommons.org/licenses/by/ $4.0 /)$.
Abstract: Magnesium alloys usually exhibit excellent superplasticity at high temperature. However, many $\mathrm{Mg}$ alloys have poor formation ability near room temperature. Therefore, preparation of $\mathrm{Mg}$ alloys with suitable microstructures to show low or intermediate temperature superplasticity is an important goal. In this work, the superplastic behavior at intermediate temperatures of a commercial ZK60 magnesium alloy processed by indirect extrusion was investigated. After extrusion, the alloy showed a refined and homogeneous microstructure with an average grain size of $4 \pm 2 \mu \mathrm{m}$. Overall texture measurement indicated that the alloy showed a strong prismatic texture with the highest intensity oriented to pole $\langle 10 \overline{1} 0\rangle$. A texture component $\langle\overline{1} 2 \overline{1} 1\rangle$ parallel to the extrusion direction was found; this type of texture is commonly observed in $\mathrm{Mg}$ alloys with rare earth additions. Tensile tests were performed at temperatures of 150,200 , and $250^{\circ} \mathrm{C}$ at three strain rates of $10^{-2}, 10^{-3}$, and $10^{-4} \mathrm{~s}^{-1}$. A very high ductility was found at $250^{\circ} \mathrm{C}$ and $10^{-4} \mathrm{~s}^{-1}$, resulting in an elongation to failure of $464 \%$. Based on calculations of the activation energy and on interpretation of the deformation mechanism map for magnesium alloys, it was concluded that grain boundary sliding (GBS) is the dominant deformation mechanism.

Keywords: magnesium alloys; texture; indirect extrusion

\section{Introduction}

Magnesium alloys are increasingly used in electronics, automotive, and aerospace industries due to their low density, high specific strength, and excellent machinability [1]. However, the hexagonal crystal structure of magnesium limits its ductility, particularly at low temperatures. Magnesium exhibits only three slip systems at low temperature. Recent studies have shown that the ductility of this alloy can be improved with the reduction of grain size, and this could lead to superplastic behavior [1-5].

Superplasticity refers to the ability of a material to achieve high elongations of at least $200 \%$ when a sample is tested in tension [6]. By definition, superplasticity allows some metals and alloys to reach extensive ductility under restricted circumstances such as (1) low strain rates (usually between $10^{-5}$ and $10^{-3} \mathrm{~s}^{-1}$ ), (2) a fine and stable microstructure, and (3) a deformation temperature around $0.5 \mathrm{Tm}$ or higher (with Tm being the absolute melting temperature) [7]. The superplastic behavior in magnesium alloys can provide the ability to deform complex parts that are difficult to form [8].

One advantage of Al-free $\mathrm{Mg}$ alloys is the exceptional grain-refining ability of $\mathrm{Zr}$. Furthermore, in combination with a severe plastic deformation process such as rolling, 
extrusion, drawing, equal channel angular pressing (ECAP), and friction stir processing (FSP), it can lead to stable fine grain structures in wrought alloys [9-13]. Among these, extrusion processes have aroused special interest, through which the microstructure can be strongly deformed, resulting in a refined microstructure and a suitable texture [13-16]. Specifically, the indirect extrusion process has shown a good combination of high strength and ductility at room temperature and superplasticity at elevated temperatures [16,17].

The purpose of this work is to investigate the superplastic behavior in a ZK60 commercial magnesium alloy processed by indirect extrusion by means of tensile tests at intermediate temperatures at three different strain rates and to elucidate the deformation mechanisms involved.

\section{Materials and Methods}

The commercial magnesium ZK60 alloy used in this study was processed by indirect extrusion, and it was provided by the consortium responsible for the MAGFORGE Project, a European Community Research on Forging of Magnesium Alloys [18]. The alloy was provided in the form of round bars of 2 in. diameter. The chemical composition of the alloy is given in Table 1.

Table 1. Alloy composition in weight percentage.

\begin{tabular}{cccc}
\hline Alloy & Mg & Zn & Zr \\
\hline ZK60 & 94.55 & 5.00 & 0.45 \\
\hline
\end{tabular}

Samples for microstructural analysis were cut from the bars in order to analyze a plane parallel to the extrusion direction, as shown in Figure 1. Subsequently, they were ground and polished with a solution of OPS (colloidal silica of $0.05 \mu \mathrm{m}$ ), using as lubricant a solution of distilled water, liquid soap, and sodium hydroxide. The chemical attack to reveal the microstructure was carried out with a picric acid solution $(150 \mathrm{~mL}$ of ethanol, $36 \mathrm{~mL}$ of distilled water, $6.5 \mathrm{~mL}$ of acetic acid, and $36 \mathrm{~g}$ of picric acid). An EBSD measurement was carried out using a field emission gun scanning electron microscope Zeiss Ultra 55 (Carl Zeiss AG, Oberkochen, Germany) equipped with an EDAX-TSL OIM system (EDAX-TSL OIM-7, Ametek-EDAX inc, Draper, UT, USA). The sample used was prepared in the same way as described above. In addition, it was electropolished using a Struers AC2 solution (Struers $\mathrm{GmbH}$, Willich, Germany) at $16 \mathrm{~V}$ for $35 \mathrm{~s}$ at $-25^{\circ} \mathrm{C}$ to obtain a surface free of defects, such as deformation from mechanical polishing and scratches. The measurement was also carried out on the extrusion direction (ED)-normal direction (ND) plane. The EBSD measurement was conducted with an acceleration voltage of $15 \mathrm{kV}$ and a step size of $0.3 \mu \mathrm{m}$.

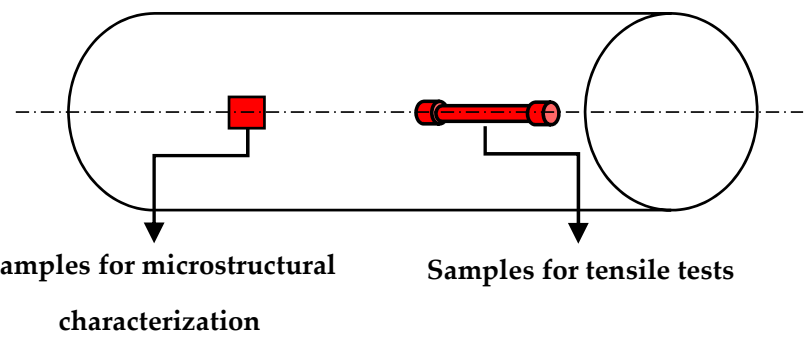

Figure 1. Location and orientation of samples for microstructural characterization and tensile tests.

The global texture was measured by means of a PANalytical X-ray diffractometer (Malvern Panalytical GmbH, Almelo, The Netherlands), using a texture goniometer and a sample in the form of a disc with a diameter of $1 \mathrm{~cm}$. Before measurement, the sample was ground and polished. The results obtained were processed with the software X'Pert Texture (Data collector 2.0, Malvern Panalytical GmbH, Almelo, The Netherlands) to obtain the pole figures. 
Tensile test samples were machined from the bars with the load direction parallel to the extrusion direction according to DIN 50125 M6, as shown in Figures 1 and 2. Tensile tests were carried out at intermediate temperatures of 150,200 , and $250{ }^{\circ} \mathrm{C}$ and strain rates of $10^{-2}, 10^{-3}$, and $10^{-4} \mathrm{~s}^{-1}$.

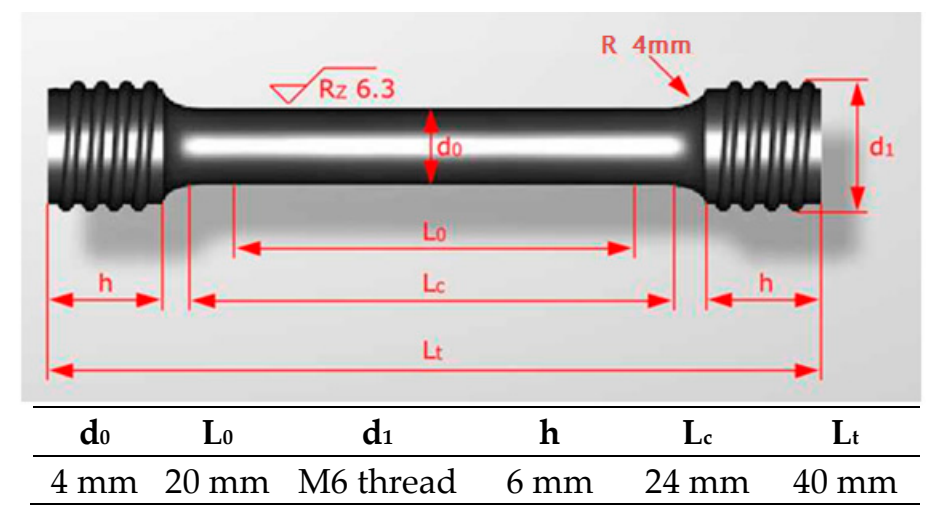

Figure 2. Dimensions of tensile samples according to DIN 50125 M6.

The heating of the tensile test samples was applied by means of an electric furnace, which kept the specimens at a constant temperature within a range of $\pm 1^{\circ} \mathrm{C}$. Before the test, the specimens were preheated to the selected temperature for $10 \mathrm{~min}$ in order to have a homogeneous and stable temperature. Once the test specimens had fractured, they were immediately quenched in water.

\section{Results and Discussion}

\subsection{Initial Microstructure and Global Texture}

The microstructure of the as-received commercial ZK60 alloy (see Figure 3a) showed recrystallized grains with an average grain size of $4 \pm 2 \mu \mathrm{m}$ measured by the linear intercept method. The microstructure showed additional bands of unrecrystalized grains. Shahzad et al. [17] studied these bands and found that they were zones of unrecrystallized grains formed by $\mathrm{Zr}$ segregations. Additionally, an analysis by EDS in SEM revealed particles rich in $\mathrm{Zr}$ and $\mathrm{Zn}$. It is possible to consider that such particles belong to the $\mathrm{Zr}_{2} \mathrm{Zn}$ phase previously identified [19].

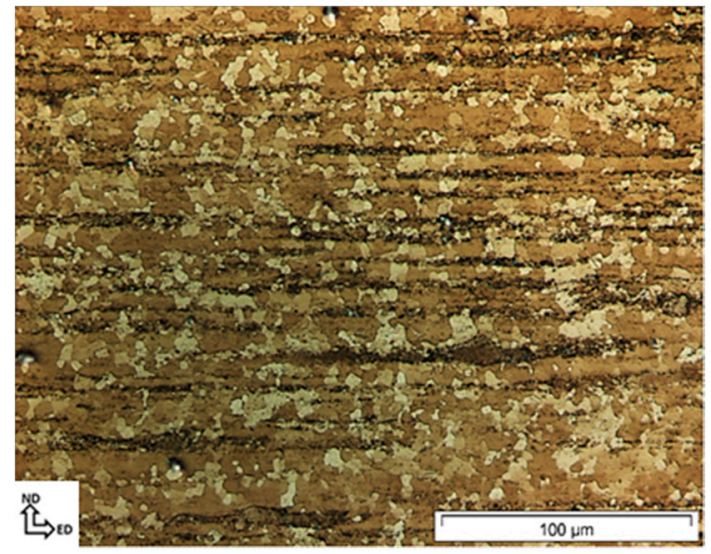

(a)

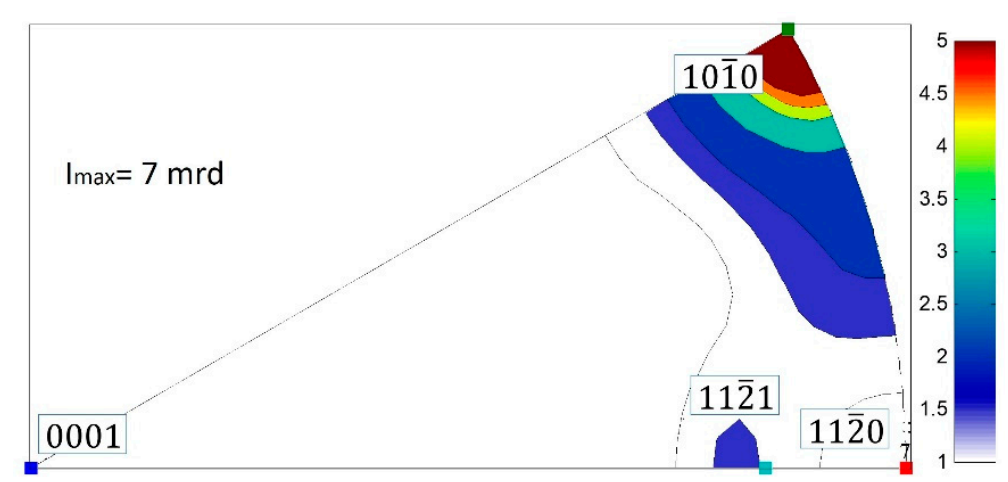

(b)

Figure 3. Microstructure of alloy ZK60 as received (a) and inverse pole figure (0001) (b).

In order to determine the texture of this alloy, pole figures of basal, prismatic, and pyramidal planes were constructed by means of X-ray diffraction. The inverse pole figures 
(IPFs) were obtained with the help of the MTEX software (Version 5.3.1, free and open source software toolbox).

The commercial ZK60 alloy showed a strong prismatic texture (see Figure 3b), and the highest intensity was found at the pole $\langle 10 \overline{1} 0\rangle$. That means that most of the grains were oriented in such a way that their basal plane was parallel to the extrusion direction.

During extrusion, a texture component $\langle 11 \overline{2} 1\rangle$ was developed parallel to the extrusion direction (ED), which caused the grains oriented in this direction to be favorable for basal slip, resulting in an improvement in ductility at room temperature [20]. This type of texture component is not often found in conventional alloys, but it has been seen more frequently in magnesium alloys with additions of rare earth (RE) elements such as $\mathrm{Ce}$, $\mathrm{Nd}, \mathrm{Gd}$, and $\mathrm{Y}[20,21]$. However, a minor influence on the mechanical behavior of this texture component in tension was expected, since most of the grains were aligned around the $\langle 10 \overline{1} 0\rangle$ pole. On the other hand, it could have contributed to a decrease in the yield asymmetry in samples tested in compression in comparison to the yield stress in tension. However, the analysis of the yield asymmetry is out of the focus of the present work. For more details on the influence of the $\langle 11 \overline{2} 1\rangle$ texture component, readers are referred to [22].

\subsection{Ductility}

Figure 4 shows the engineering stress-strain curve of ZK60 magnesium alloy at room temperature at a strain rate of $10^{-3} \mathrm{~s}^{-1}$. As a result, the material presented a yield stress $=223 \mathrm{MPa}$, UTS $=290 \mathrm{MPa}$, and a ductility of $\sim 13 \%$. These data agree with the literature [20].

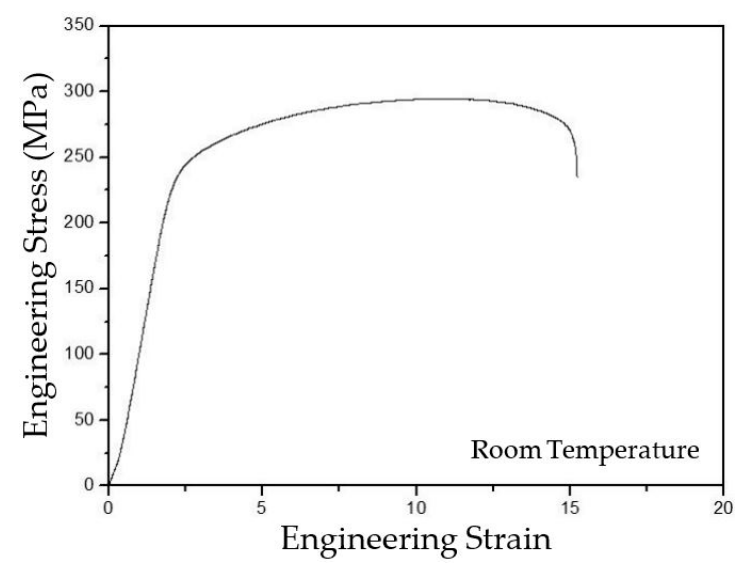

Figure 4. Stress-strain curve at strain rate of $10^{-3} \mathrm{~s}^{-1}$ for alloy ZK60.

At a temperature of $150^{\circ} \mathrm{C}$ with a strain rate of $10^{-2} \mathrm{~s}^{-1}$, the commercial ZK60 alloy exhibited a good ductility of $49 \%$. As the strain rate decreased, the ductility increased, reaching an elongation to fracture of $89 \%$ at the lowest strain rate (see Figure 5). On the other hand, the yield stress and peak stress decreased as the strain rate decreased, while elongation to fracture increased, as shown in Figures 6 and 7. When increasing the test temperature to $200^{\circ} \mathrm{C}$, the behavior was very similar to that observed at the temperature of $150{ }^{\circ} \mathrm{C}$, and at the lowest strain rate tested, an elongation to fracture of $137 \%$ was obtained.

Finally, at the highest test temperature used in this work $\left(250{ }^{\circ} \mathrm{C}\right)$ and a strain rate of $10^{-4} \mathrm{~s}^{-1}$, superplastic behavior was observed in this alloy, since it reached $464 \%$ of elongation to fracture. Several authors have already reported large percentages of elongation for this alloy. For example, W.J. Kim [23] reported $~ 1000 \%$ with a temperature of $250{ }^{\circ} \mathrm{C}$ and strain rate of $10^{-3} \mathrm{~s}^{-1}$ and attributed this percentage to a very fine grain size of $1.4 \mu \mathrm{m}$ obtained by differential speed rolling. H. Watanabe et al. [24] also obtained a refined microstructure with a grain size of $1.4 \mu \mathrm{m}$ processed by equal channel angular extrusion (ECAE) that reached elongation percentages above $400 \%$ at low strain rates and a temperature of $200{ }^{\circ} \mathrm{C}$. The value reached in this study turns out to be quite acceptable, since this alloy was processed by conventional indirect extrusion and deformed at low temperature. 

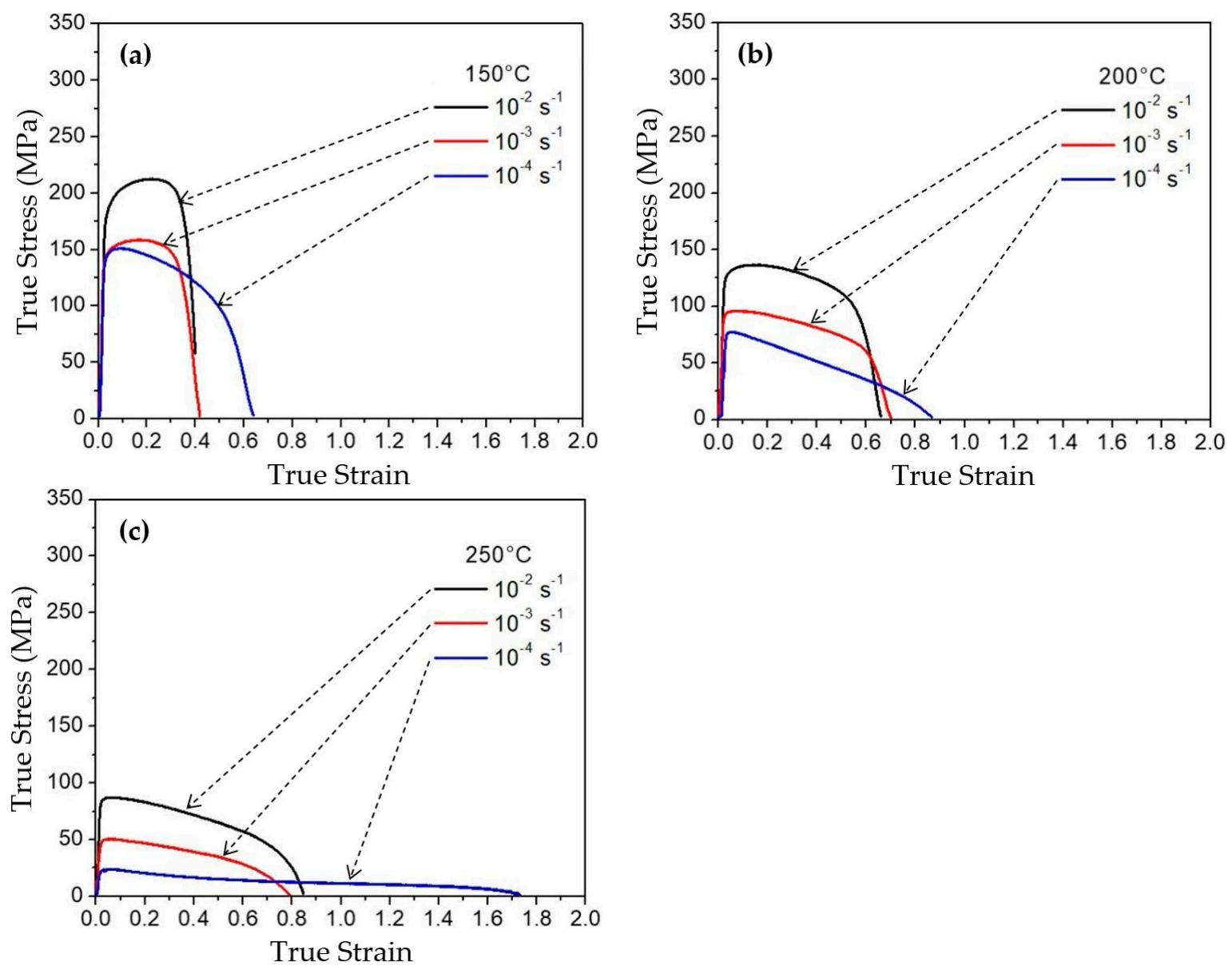

Figure 5. True stress-true strain curves at different temperatures and strain rates: (a) 150, (b) 200, and (c) $250{ }^{\circ} \mathrm{C}$.
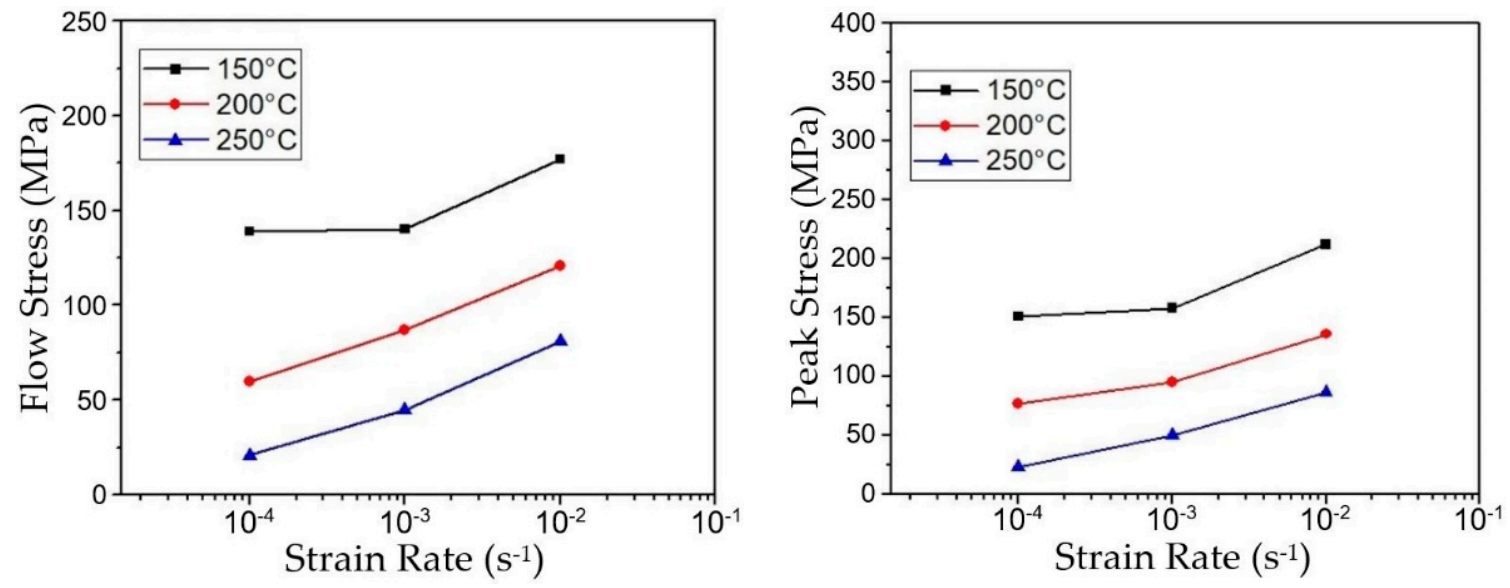

Figure 6. Flow and peak stress as a function of strain rate at different temperatures.

The samples deformed in tension at intermediate temperatures and three different strain rates, as well as at room temperature, are shown in Figure 8. In general, the samples present a ductile fracture. This type of fracture occurs when the material is subjected to a severe or excessive plastic deformation. In addition, this type of fracture can be recognized by the characteristic neck formation in the fractured area; however, this neck was less pronounced at lower strain rates. This is especially noticeable in the sample that reached superplastic-like behavior in which a rather diffuse neck can be observed. 


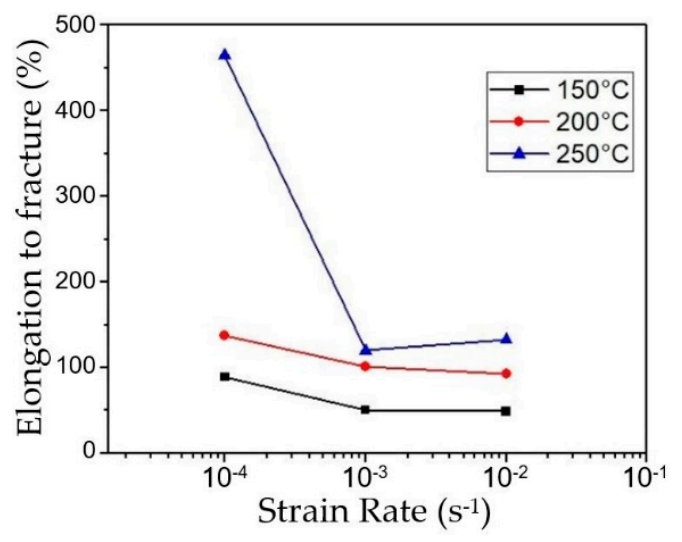

Figure 7. Elongation to fracture as a function of strain rate at different temperatures.

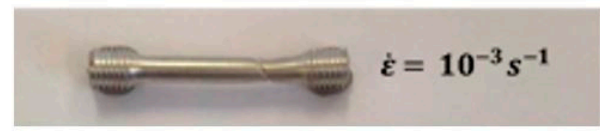

(a)

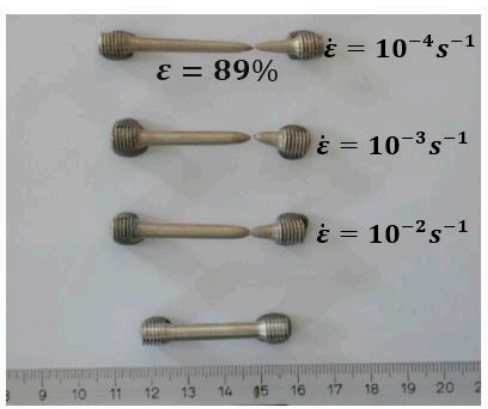

(b)

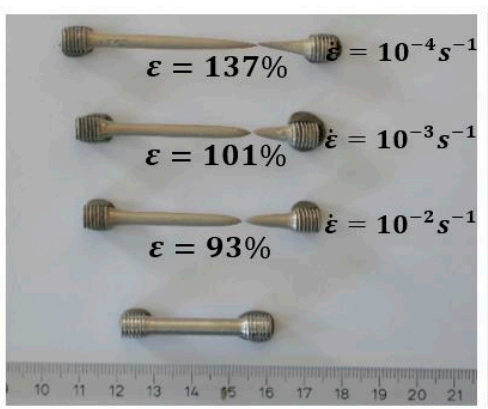

(c)

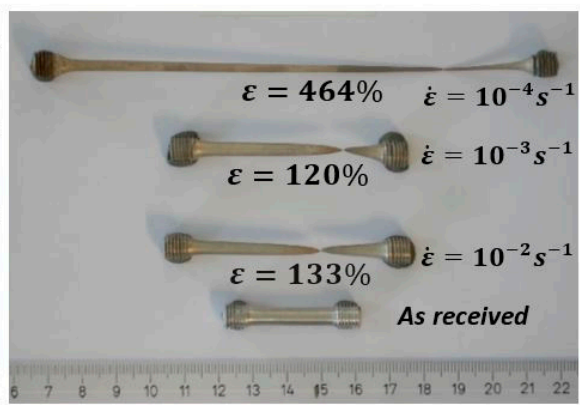

(d)

Figure 8. Appearance of tensile specimens after deformation to failure at (a) room temperature and at (b) 150, (c) 200, and (d) $250{ }^{\circ} \mathrm{C}$ under various strain rates.

\subsection{Microstructure after Deformation}

The microstructural changes observed after the elongation to failure tests are shown in Figures 9 and 10. The sample tested at room temperature shows a deformed microstructure with some signs of twinning inside the relatively large unrecrystallized grains. This is despite the initial texture in which the majority of grains have a basal-type texture. However, it should be mentioned that the micrograph was taken near the fracture. Thus, some instabilities due to necking could occur, which could have led to the twinning behavior (see Figure 9). Moreover, due to the initial texture with some off-basal texture components, the activation of $\{10 \overline{1} 2\}$ extension twins was feasible. At elevated temperatures (see Figure 10), the micrographs show a fine-grained structure, especially above $200{ }^{\circ} \mathrm{C}$. At a temperature of $150{ }^{\circ} \mathrm{C}$, the grain was refined as the strain rate decreased. A very different behavior was observed at $200^{\circ} \mathrm{C}$, since the smallest grain size was found at the highest strain rate. It is clearly observed that the dynamic recrystallization process was present as the strain rate decreased, obtaining a homogeneous microstructure at $250^{\circ} \mathrm{C}$ and $10^{-4} \mathrm{~s}^{-1}$. Despite the coarser grain size in comparison to samples deformed at higher strain rates at $250{ }^{\circ} \mathrm{C}$, this sample achieved the highest ductility in this study.

Figure 11 exhibits an inverse pole figure map and respective local texture of a sample deformed at $250{ }^{\circ} \mathrm{C}$ and a strain rate of $10^{-4} \mathrm{~s}^{-1}$. Despite the fact that a high elongation to fracture was reached and that a significant dynamic recrystallization took place, the deformation texture shared many similarities with the initial texture; i.e., it retained the majority of grains oriented near the $\langle 10 \overline{1} 0\rangle$ pole with no obvious development of the $\langle 112 \overline{1}\rangle$ 
texture component. However, an important texture-weakening was observed, most likely because of the combined activity of dynamic recrystallization and the activation of grain boundary sliding (GBS).

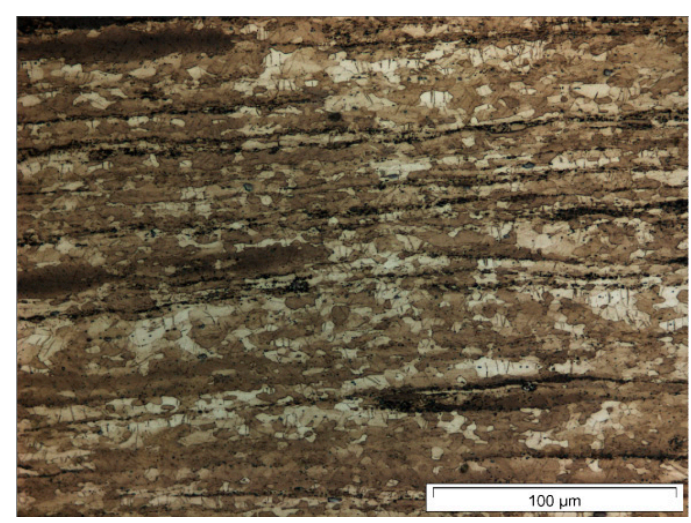

Figure 9. Microstructure obtained near the fractured zone after tensile test at room temperature and strain rate of $10^{-3} \mathrm{~s}^{-1}$.
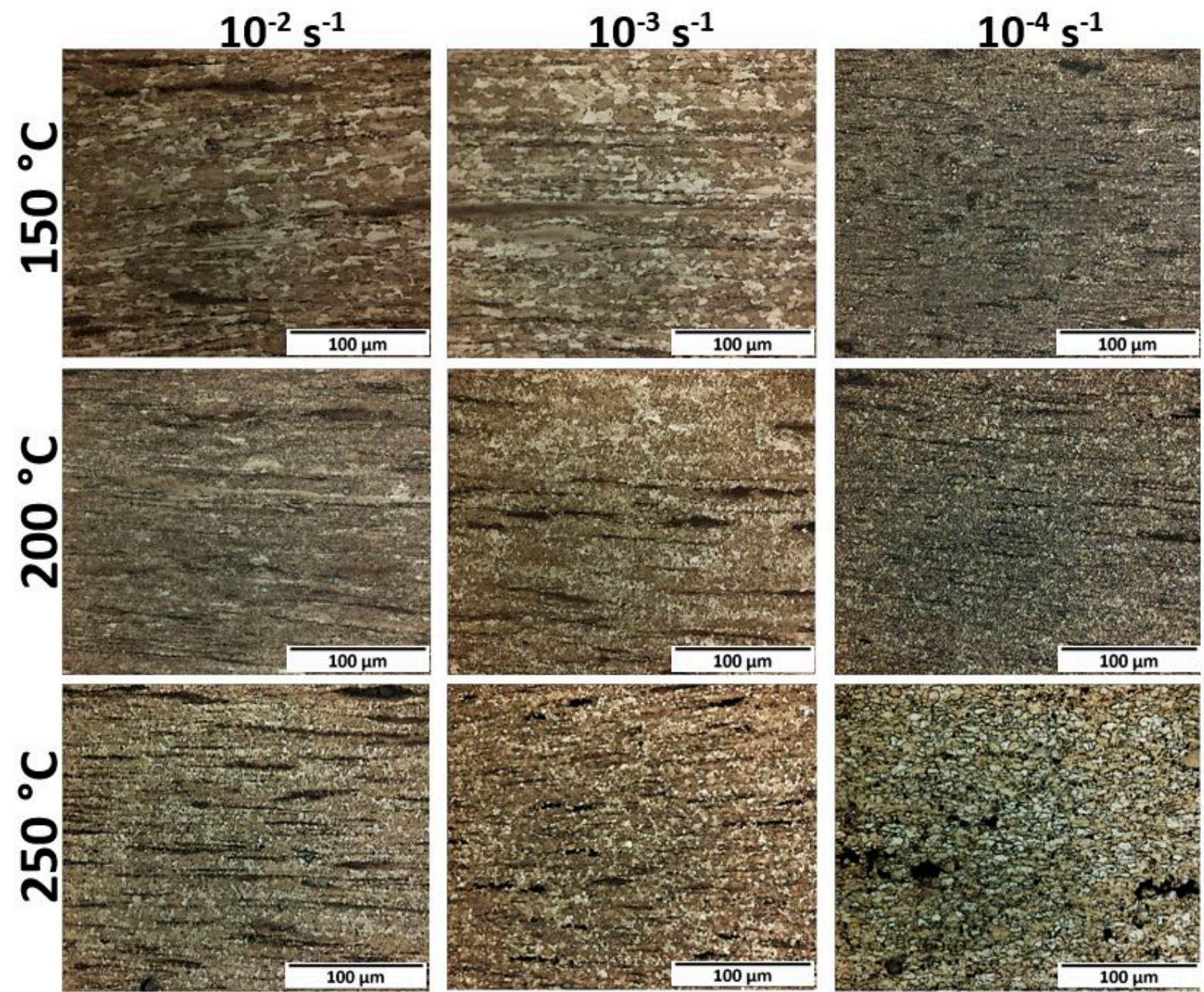

Figure 10. Microstructures obtained near the fractured zone after tensile tests at different temperatures and strain rates. 


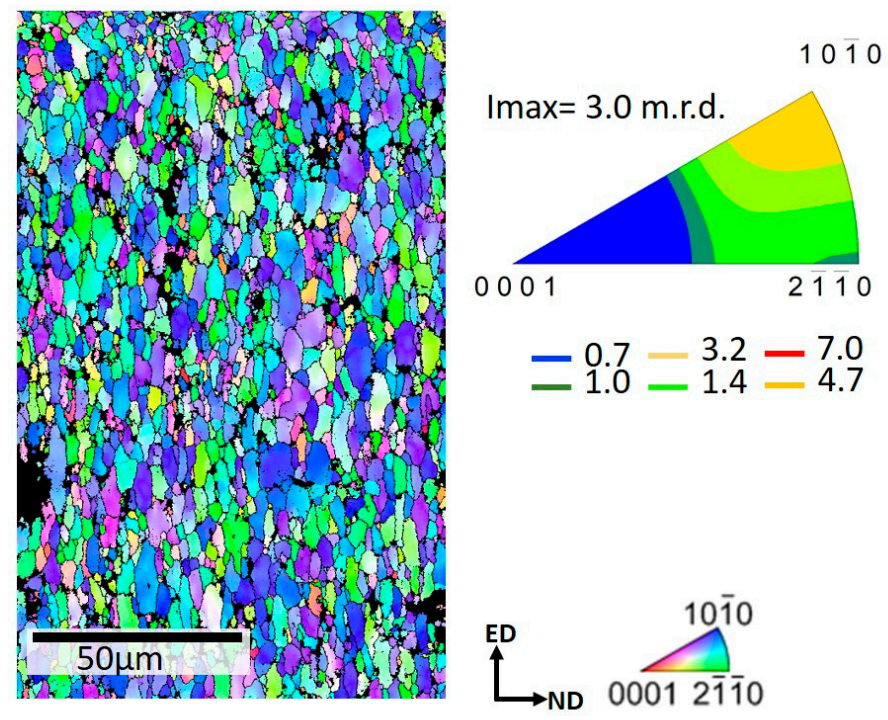

Figure 11. Inverse pole figure map and respective local texture measured near the fracture of a sample deformed at $250{ }^{\circ} \mathrm{C}$ and a strain rate of $10^{-4} \mathrm{~s}^{-1}$.

\subsection{Zener-Hollomon Parameter}

In order to analyze the different values of mechanical properties obtained after the tensile tests, the Zener-Hollomon parameter was calculated for this alloy. The determination of this value $(Z)$ was based on the study carried out by Liu et al. [25], according to the following equation:

$$
Z=\dot{\varepsilon} \cdot \exp \left(\frac{Q}{R T}\right)=A \cdot(\sinh (\alpha \sigma))^{n}
$$

where $\mathrm{Z}$ is the temperature-compensated strain rate (i.e., the Zener-Hollomon parameter); $\dot{\varepsilon}$ is the strain rate; $Q$ is the activation energy; $\mathrm{R}$ is the gas constant; $\mathrm{T}$ is the absolute temperature; and $A, \alpha$, and $n$ are material constants. It was assumed that the relationship of the Zener-Hollomon parameter and the steady-rate stress were suitable for Equation (1). The values of $A, \mathrm{y}$, and $n$ can be obtained from the plot of $\ln (\sinh (\alpha \sigma))$ versus $\ln Z$. However, the values of $\alpha$ and $Q$ must be determined before the values of $A$ and $n$ are fixed. The approximate value of $\alpha$ is determined as follows.

The hot working favored the power law at high stress levels, and the equation is presented as follows:

$$
Z \approx A_{1} \sigma^{n \prime}
$$

The favored equation is the exponent law at low stress levels, which is given by

$$
Z \approx A_{2} \exp (\beta \sigma)
$$

Assuming the value of $n \prime=n$, the approximate value of $n$ can be taken as the slope of the plot of $\ln \sigma$ versus $\ln \dot{\varepsilon}$ at low stress levels. It can be seen by comparing Equation (1) with Equation (3) that $A=A_{2} / 2^{n}$ and the value of $\alpha=\beta / n$. The values of $A_{2}$ and $\beta$ can be determined according to the $\sigma$ versus $\ln \dot{\varepsilon}$ plot at high stress levels. It should also be noted that $\sigma$ can be referred to as the peak stress $\sigma_{p}$ [26], which is easier to obtain; therefore, it is the stress used in this study. The value of $Q$ is calculated in the following equation:

$$
Q=R\left[\frac{\partial \ln \left(\sinh \left(\alpha \sigma_{p}\right)\right)}{\partial(1 / T)}\right]_{\dot{\varepsilon}} \cdot\left[\frac{\partial \ln \dot{\varepsilon}}{\partial \ln \left(\sinh \left(\alpha \sigma_{p}\right)\right)}\right]_{T}
$$

On the right-hand side of the above equation, the first term represents the slope of the $\ln \left(\sin h\left(\alpha \sigma_{p}\right)\right)$ versus $1 / T$ plot, called $\mathrm{q}_{1}$, while the second term represents the reciprocal value of inclination of the $\ln \left(\sin h\left(\alpha \sigma_{p}\right)\right)$ versus $\ln \dot{\varepsilon}$ plot, called $1 / \mathrm{q}_{2}$. 
The exact values of $A$ and $n$ are obtained from the plot $\ln \left(\sin h\left(\alpha \sigma_{p}\right)\right)$ versus $\ln Z$, being the relationship of $\sigma_{p}$ and $Z$ as follows:

$$
\ln (Z)=\ln (A)+n \cdot \ln \left(\sinh \left(\alpha \sigma_{p}\right)\right)
$$

In this way, the approximate values of $n$ and $\beta$ are estimated from Figure 12a,b, respectively. So, the value of $\alpha$ is 0.0056 . On the other side, $\mathrm{q}_{1}$ and $1 / \mathrm{q}_{2}$ are obtained from Figure 12c,d, respectively. As a result, the average value of $Q$ is $466.1 \mathrm{~kJ} / \mathrm{mol}$. Now, substituting $Q, \mathrm{R}, \mathrm{T}$, and $\dot{\varepsilon}$ in Equation (1), the values of $\ln Z$ can be obtained, which are in the range of 50 to 250. Finally, the exact values of $A$ and $n$ are obtained from the $\ln \left(\sinh \left(\alpha \sigma_{p}\right)\right)$ versus $\ln Z$ plot (see Figure $12 \mathrm{~d}$ ), where $n$ is 84.81 and $\ln A$ is 58.52.
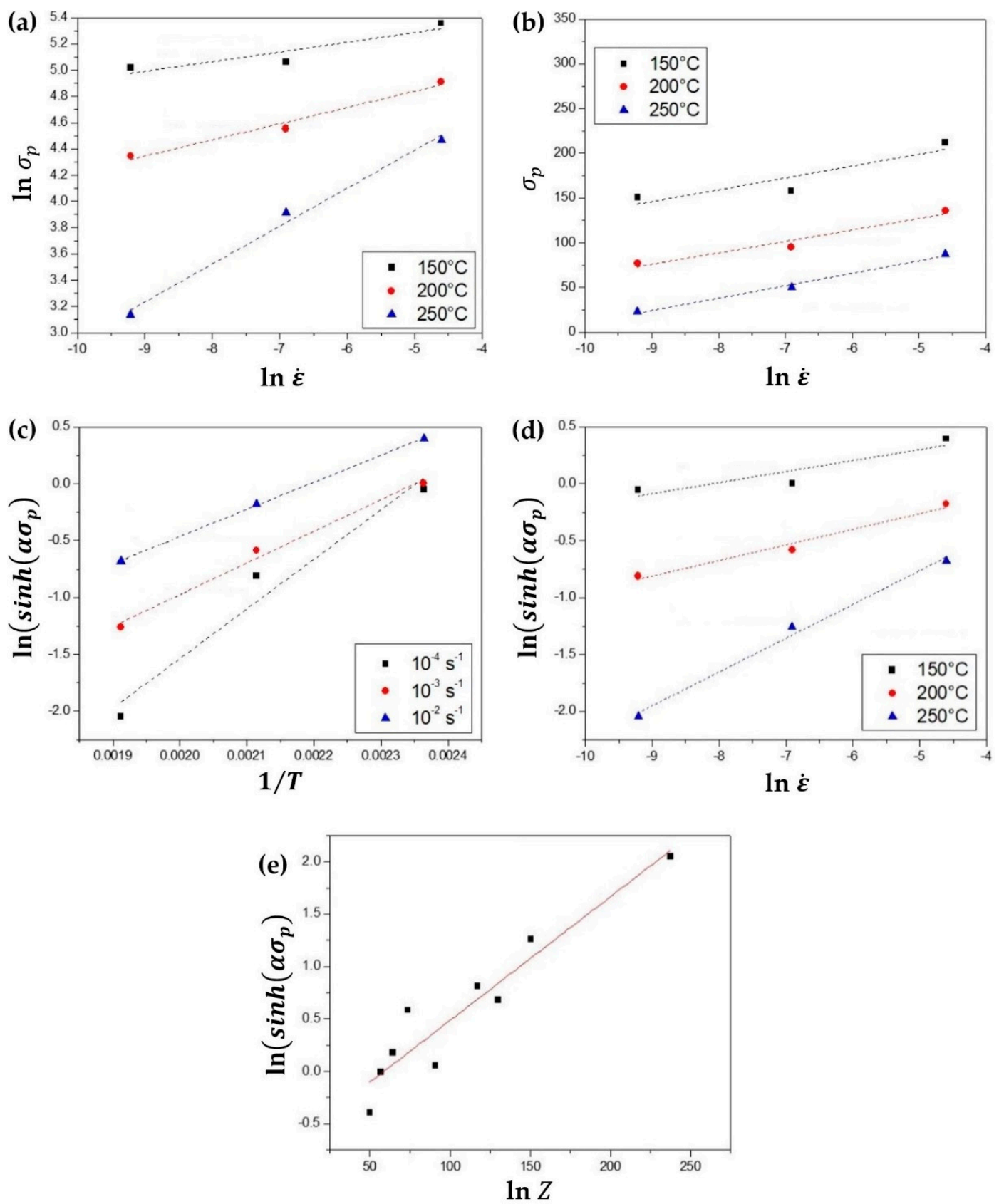

Figure 12. Schematic of the dependence of the peak stress on temperature and strain rate. Plots of (a) $\ln \sigma_{p}$ versus $\ln \dot{\varepsilon},(\mathbf{b}) \sigma_{p}$ versus $\ln \dot{\varepsilon},(\mathbf{c}) \ln \left(\sinh \left(\alpha \sigma_{p}\right)\right)$ versus $1 / T,(\mathbf{d}) \ln \left(\sinh \left(\alpha \sigma_{p}\right)\right)$ versus $\ln \dot{\varepsilon}$, and $(\mathbf{e}) \ln \left(\sinh \left(\alpha \sigma_{p}\right)\right)$ versus $\ln Z$. 
The calculation of the activation energy allows an estimation of the deformation mechanism that predominates during the deformation under different conditions of strain rate and temperature. Based on the obtained average activation energy of $466.1 \mathrm{~kJ} / \mathrm{mol}$ through the range of strain rates and temperature, the dominant deformation mechanism in the present alloy is grain boundary sliding (GBS) [27].

Another way to establish the dominant deformation mechanism involved in this alloy is through the method developed by Kim et al. [3,4].

Several criteria must be met to expect the material to behave superplastically [28], and this alloy meets some of the requirements. For example, it has a fine and stable microstructure at the end of the tensile test at $250{ }^{\circ} \mathrm{C}$ and $10^{-4} \mathrm{~s}^{-1}$ with an average grain size of $\sim 4 \mu \mathrm{m}$, and there is the presence of second-phase particles that inhibit grain growth. On the other hand, superplastic materials generally exhibit high values of strain rate sensitivity " $m$ " during stress-strain tests [27-29], which is expressed by the following equation $[8,28,30]$ :

$$
\sigma=k \dot{\varepsilon}^{m}
$$

where $\sigma$ is the true flow stress, $\mathrm{k}$ is a constant, and $\dot{\varepsilon}$ is the strain rate. Metals normally exhibit $m<0.2$ and superplastic alloys commonly have values of $m>0.33$. However, the commercial ZK60 alloy of this study that obtained $464 \%$ elongation atfracture has a value of $m=0.29$.

Bussiba et al. [31] reported an elongation of $220 \%$ at a strain rate of $1 \times 10^{-5} \mathrm{~s}^{-1}$ in a ZK60 alloy with a value of $m=0.2$; they concluded that grain boundary sliding (GBS) was the dominant deformation mechanism.

H. Watanabe [24] demonstrated a superplastic behavior in a conventional ZK60 alloy by reporting an elongation greater than $400 \%$ during tension in the temperature range from 200 to $225^{\circ} \mathrm{C}$ and strain rates from $2.6 \times 10^{-6}$ to $3 \times 10^{-5} \mathrm{~s}^{-1}$ with values of $m=0.5$.

For the determination of the deformation mechanism that predominates during deformation, a deformation mechanism map (DMM) created by Kim et al. [3] was used, since this is valid for magnesium alloys in general, according to the author mentioned. The calculation of the activation energy allows for an estimation of the deformation mechanism that predominates during the deformation under different conditions of strain rate and temperature.

It was observed that the deformation mechanisms that were activated during tensile tests for ZK60 alloys were dislocation glide and grain boundary sliding (GBS), depending on the test conditions. As the stress decreased (at lower strain rates), the grain boundary sliding (GBS) was activated.

Although the DMM created by Kim et al. [3] did not correspond to that of the ZK series alloys, it provided a close estimate for magnesium-based alloys in general.

It can be established that as $\ln Z$ decreases, the elongation to fracture will increase with a concomitant decrease of the peak stress (see Figure 13). A similar case was reported by Victoria-Hernández et al. [32]. For an AZ31 alloy with a ductility above $400 \%, \ln Z$ was 19, while for an AZ61 alloy with a ductility above $500 \%$, ln $Z$ had a value of 28 - much lower values when compared to the alloys studied in this work. On the other hand, the maximum stress values are much higher in this work when compared to the study by Victoria-Hernández et al. [32], due to the strengthening effect of the alloying elements where Zr played an important role in controlling the grain size even after the occurrence of dynamic recrystallization. 


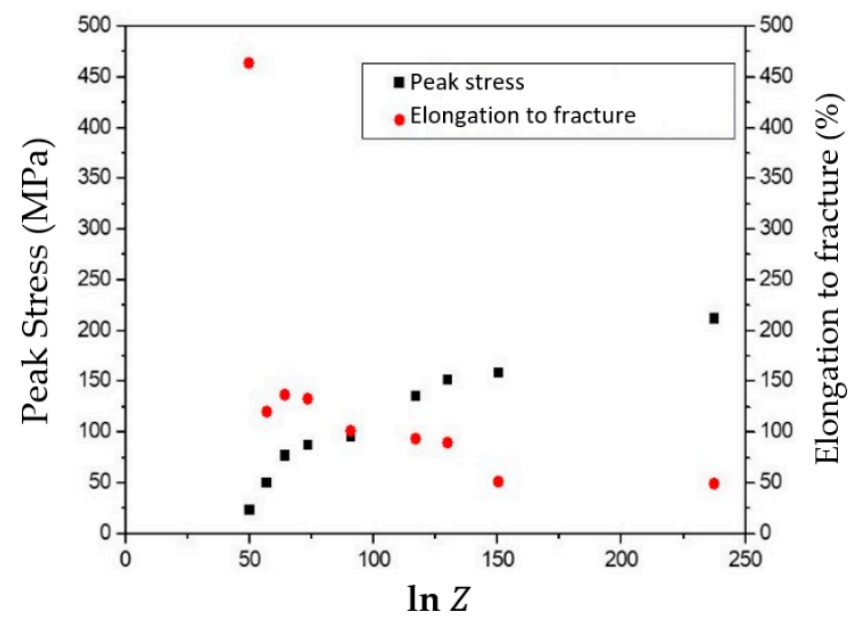

Figure 13. Tensile strength and elongation to failure versus $\ln Z$ plot.

\section{Conclusions}

A homogeneous and refined microstructure with a grain size of $4 \pm 2 \mu \mathrm{m}$ was obtained after conventional thermomechanical treatment and attributed to the amount of zirconium. The overall texture results show the development of the conventional basal texture where most of the basal planes are aligned parallel to ED. The texture component $\langle\overline{1} 2 \overline{1} 1\rangle$ was observed parallel to the extrusion direction; this type of texture is commonly observed in $\mathrm{Mg}$ alloys with rare earth (RE) additions. However, it did not seem to play a significant role during further tensile deformation at room temperature and after tensile tests at elevated temperatures. There was no strengthening of the aforementioned pole, even in the case of a sample deformed under a superplastic regime.

The commercial ZK60 alloy showed excellent ductility at $250{ }^{\circ} \mathrm{C}$ at three different strain rates, especially at the slowest strain rate $\left(10^{-4} \mathrm{~s}^{-1}\right)$. This alloy was able to present a superplastic behavior, as it achieved a peak elongation of $464 \%$, which is explained due to the combined effect of dynamic recrystallization and the likely activation of GBS. The latter mechanism was believed to be dominant during tests at $250{ }^{\circ} \mathrm{C}$ temperature and slow strain rates. As calculated, the activation energy indicates the feasible activation of this mechanism. Furthermore, the texture-weakening effect found in the sample deformed under a superplastic regime suggests the dominant activation of this deformation mechanism. By increasing the strain rate or reducing the temperature, the dominant deformation mechanism seemed to change to dislocation glide.

Author Contributions: Conceptualization, J.V.-H. and C.P.-T.; methodology, J.V.-H. and C.P.-T.; formal analysis, C.P.-T. and D.H.-S.; investigation, C.P.-T.; writing-original draft preparation, M.A.G.B.; writing-review and editing, M.A.G.-B. and D.H.-S.; visualization, M.A.G.-B..; supervision, D.H.S.; project administration, D.L. and J.V.-H.; funding acquisition, D.L. All authors have read and agreed to the published version of the manuscript.

Funding: This research received no external funding.

Data Availability Statement: Data supporting reported results can be shared on a reasonable request to corresponding authors.

Acknowledgments: C.P.-T. is grateful for the fruitful discussions with J. Bohlen during his research stay at HZG. C.P.-T. also acknowledges the economic support (Becas Mixtas) of CONACyT-Mexico for his research stay in Germany. The technical support of Y. Shin and A. Reichert at HZG is gratefully acknowledged.

Conflicts of Interest: The authors declare no conflict of interest. 


\section{References}

1. Zheng, M.; Wu, K.; Liang, M.; Kamado, S.; Kojima, Y. The effect of thermal exposure on the interface and mechanical properties of Al18B4O33w / AZ91 magnesium matrix composite. Mater. Sci. Eng. A 2004, 372, 66-74. [CrossRef]

2. Panicker, R.; Chokshi, A.; Mishra, R.; Verma, R.; Krajewski, P. Microstructural evolution and grain boundary sliding in a superplastic magnesium AZ31 alloy. Acta Mater. 2009, 57, 3683-3693. [CrossRef]

3. Kim, W.-J.; Chung, S.; Chung, C.; Kum, D. Superplasticity in thin magnesium alloy sheets and deformation mechanism maps for magnesium alloys at elevated temperatures. Acta Mater. 2001, 49, 3337-3345. [CrossRef]

4. Kim, W.J.; Park, J.D.; Yoon, U.S. Superplasticity and superplastic forming of Mg-Al-Zn alloy sheets fabricated by strip cast-ing method. J. Alloys Compd. 2008, 464, 197-204. [CrossRef]

5. Watanabe, H.; Fukusumi, M. Mechanical properties and texture of a superplastically deformed AZ31 magnesium alloy. Mater. Sci. Eng. A 2008, 477, 153-161. [CrossRef]

6. Watanabe, H.; Fukusumi, M.; Somekawa, H.; Mukai, T. Texture and mechanical properties of superplastically deformed magnesium alloy rod. Mater. Sci. Eng. A 2010, 527, 6350-6358. [CrossRef]

7. Raghavan, K.S. Superplasticity. Bull. Mater. Sci. 1984, 6, 689-698. [CrossRef]

8. Padmanabhan, K.A.; Vasin, R.A.; Enikeev, F.U. Superplastic Flow, Phenomenology and Mechanics, 1st ed.; Springer: Berlin/Heidelberg, Germany, 2001.

9. Zhou, H.; Ye, B.; Wang, Q.; Guo, W. Uniform fine microstructure and random texture of Mg-9.8Gd-2.7Y-0.4Zr magnesium alloy processed by repeated-upsetting deformation. Mater. Lett. 2012, 83, 175-178. [CrossRef]

10. Valive, R.Z.; Langdon, T.G. Principles of equal-channel angular pressing as a processing tool for grain refinement. Prog. Mater. Sci. 2006, 51, 881-981. [CrossRef]

11. Yu, Y.; Kuang, S.; Chu, D.; Zhou, H.; Li, J.; Li, C. Microstructure and Low-Temperature Superplasticity of Fine-Grain ZK60 Magnesium Alloy Produced by Equal-Channel Angular Pressing. Met. Microstruct. Anal. 2015, 4, 518-524. [CrossRef]

12. García-Bernal, M.A.; Mishra, R.S.; Verma, R.; Hernández-Silva, D. Influence of friction stir processing tool design on microstructure and superplastic behavior of Al-Mg alloys. Mater. Sci. Eng. A 2016, 670, 9-16. [CrossRef]

13. Zhanga, T.; Cuia, H.; Cuia, X.; Chenb, H.; Zhaoc, E.; Changd, L.; Pana, Y.; Fenga, R.; Zhaie, S.; Chai, S. Effect of addition of small amounts of samariumon microstructural evolution and mechanical properties enhancement of an as-extruded ZK60 magnesium alloy sheet. J. Mater. Res. Technol. 2020, 9, 133-141. [CrossRef]

14. Zhou, W.; Lin, J.; Dean, T.A.; Wang, L. Feasibility studies of a novel extrusion process for curved profiles: Experimentation and modelling. Int. J. Mach. Tools Manuf. 2018, 126, 27-43. [CrossRef]

15. Zhou, W.; Yu, J.; Lin, J.; Dean, T.A. Manufacturing a curved profile with fine grains and high strength by differential velocity sideways extrusion. Int. J. Mach. Tools Manuf. 2019, 140, 77-88. [CrossRef]

16. Kim, B.; Baek, S.; Lee, J.; Park, S. Enhanced strength and plasticity of Mg-6Zn-0.5Zr alloy by low-temperature indirect extru-sion. J. Alloys Compd. 2017, 706, 56-62. [CrossRef]

17. Shahzad, M.; Wagner, L. Microstructure development during extrusion in a wrought Mg-Zn-Zr alloy. Scr. Mater. 2009, 60, 536-538. [CrossRef]

18. Sillekens, W.H.; Letzig, D. The MAGFORGE Project: European Community research on forging of magnesium alloys. In Proceedings of the 7th International Conference on Magnesium Alloys and their Applications, Dresden, Germany, 6-9 November 2006.

19. Friedrich, H.E.; Mordike, B.L. Magnesium Technology, Metallurgy, Design Data, Applications; Springer: Berlin/Heidelberg, Germany, 2006.

20. Jiang, M.; Xu, C.; Nakata, T.; Yan, H.; Chen, R.; Kamado, S. Rare earth texture and improved ductility in a Mg-Zn-Gd alloy after high-speed extrusion. Mater. Sci. Eng. A 2016, 667, 233-239. [CrossRef]

21. Luo, A.A.; Mishra, R.K.; Sachdev, A.K. High-ductility magnesium-zinc-cerium extrusion alloys. Scr. Mater. 2011, 64, 410-413. [CrossRef]

22. Cano-Castillo, G.; Victoria-Hernández, J.; Bohlen, J.; Letzig, D.; Kainer, K.U. Effect of Ca and Nd on the microstructural development during dynamic and static recrystallization of indirectly extruded Mg-Zn based alloys. Mater. Sci. Eng. A 2020, 793, 139527. [CrossRef]

23. Kim, W.J.; Kim, M.J.; Wang, J.Y. Superplastic behavior of a fine-grained ZK60 magnesium alloy processed by high-ratio dif-ferential speed rolling. Mater. Sci. Eng. A 2009, 527, 322-327. [CrossRef]

24. Watanabe, H.; Mukai, T.; Ishikawa, K.; Higashi, K. Low temperature superplasticity of a fine-grained ZK60 magnesium alloy processed by equal-channel-angular extrusion. Scr. Mater. 2002, 46, 851-856. [CrossRef]

25. Liu, J.; Cui, Z.; Li, C. Modelling of flow stress characterizing dynamic recrystallization for magnesium alloy AZ31B. Comput. Mater. Sci. 2008, 41, 375-382. [CrossRef]

26. McQueen, H.; Ryan, N. Constitutive analysis in hot working. Mater. Sci. Eng. A 2002, 322, 43-63. [CrossRef]

27. Frost, H.J.; Ashby, M.F. Deformation Mechanism Maps: The Plasticity and Creep of Metals and Ceramics; Pergamon Press: Oxford, UK, 1982.

28. Sherby, O.D.; Wadsworth, J. Superplasticity-Recent advances and future directions. Prog. Mater. Sci. 1989, 33, 169-221. [CrossRef] 
29. Olguín-González, M.; Hernández-Silva, D.; García-Bernal, M.; Sauce-Rangel, V. Hot deformation behavior of hot-rolled AZ31 and AZ61 magnesium alloys. Mater. Sci. Eng. A 2014, 597, 82-88. [CrossRef]

30. Edington, J.W.; Melton, K.N.; Cutler, C.P. Superplasicity. Prog. Mater. Sci. 1976, 21, 61-170. [CrossRef]

31. Bussiba, A.; Ben Artzy, A.; Shtechman, S.; Ifergan, M. Kupiec. Grain refinement of AZ31 and ZK60 Mg alloys - towards superplasticity studies. Mater. Sci. Eng. A. 2001, 302, 56-62. [CrossRef]

32. Victoria-Hernández, J.; Yi, S.; Letzig, D.; Hernández, D.; Bohlen, J. Microstructure and texture development Mg-Al-Zn alloys during tensile testing at intermediate temperatures. Acta Mater. 2013, 61, 2179-2193. [CrossRef] 